\title{
Releer la polémica Simiand-Seignobos: método, ciencia y lucha por la hegemonía disciplinar en el campo de las ciencias humanas en Francia
}

\author{
David J. Domínguez \\ Universidad Complutense de Madrid. Departamento de Sociología: metodología y teoría \\ dadomi01@ucm.es
}

\section{Resumen}

En 1903, el sociólogo francés François Simiand imparte una polémica conferencia en contra de los fundamentos del método historiográfico. En ella arremete contra los tres ídolos (político, individual, cronológico) que, a su parecer, impedían la conversión de la historia en un saber científico. Tal ataque, sin embargo, no encontró una respuesta inmediata de su parte, si bien es cierto que las críticas posteriores de Simiand acabaron por motivar la respuesta de uno de los historiadores más eminentes de la época, Charles Seignobos, dando así lugar a uno de los debates más sonados en la historia de las ciencias sociales. El propósito del presente artículo consiste en retomar este célebre debate, pero de un modo estratégico. Lejos de realizar un mero resumen al uso de la disputa, se procederá a una reinterpretación crítica de la misma, tratando de insertar los argumentos de los interlocutores a la luz de tres ejes básicos de debate: el método, el modelo de ciencia y la disputa en torno al lugar que debe ocupar la ciencia histórica o la sociología en la clasificación de las ciencias sociales.

Palabras clave: epistemología; sociología; historiografía; Simiand; Durkheim

\section{Abstract. Rereading the Ch. Seignobos-F. Simiand polemic: Method, science and struggle for} disciplinary hegemony in the field of human sciences in France

François Simiand delivered a controversial lecture on the foundations of the historiographical method, in which he called into question the three idols that, in his opinion, hindered the conversion of history into a form of scientific knowledge. While it is true that Simiand's arguments were not followed by immediate reactions, later critiques contributed to the work of one of the most prominent historians of the time, Ch. Seignobos, thus paving the way to one of the most debated issues in the history of social sciences. Far from proposing a summary of the debate, this article attempts to critically reinterpret it by situating the different arguments at stake within three axes: the method, the type of science, and the criterion that should guide the relationship between different human sciences.

Keywords: epistemology; social sciences; historiography; Simiand; Durkheim 


\section{Sumario}

1. Introducción y presentación del tema

2. Delimitando el terreno: antecedentes y cronología del debate

3. Un debate con estilos argumentales diferentes
4. El método en disputa: la historia será sociológica o no será

5. Conclusión

Referencias bibliográficas

\section{Introducción y presentación del tema}

El periodo que va de 1890 a 1914 es testigo de continuos debates en el campo de las ciencias sociales y el saber histórico. Basta echar un vistazo a las principales publicaciones de la época para reparar en la magnitud del asunto: todas ellas estaban repletas de interrogantes que manifestaban una clara sensibilidad metodológica. ${ }^{1}$ Las cuestiones se sucedían por doquier: ¿cómo y en qué condiciones el trabajo histórico puede convertirse en ciencia?, ¿`cuál es el objeto del saber histórico?, ¿qué significa explicar en historia?, ¿qué relación debe tener el saber histórico con el resto de las ciencias sociales?, ¿¿debe ocupar un lugar rector o ha de convertirse en una ciencia auxiliar al servicio de otro saber más abstracto, como la sociología?

He aquí el tipo de polémicas que definían el marco en el que se instaló gran parte de la reflexión historiográfica. El significante historia se convertía así en un objeto de reflexión obligado. Numerosos investigadores fueron interpelados a discutir el estatuto de la disciplina histórica o los límites de sus mecanismos de imputación causal. De todas esas discusiones, hay una sin embargo que merece una especial atención: hablamos de la polémica sobre el método histórico que tuvo lugar entre Charles Seignobos y François Simiand. Una polémica, como se sabe, dirigida no tanto contra el saber histórico en cuanto tal, sino contra las múltiples formas de determinismo que estaban en la base de la preceptiva metodológica planteada por los historiadores.

Nuestro cometido en este artículo no consiste pues en hacer un resumen al uso de la disputa; se trata, por el contrario, de reinterpretar sus argumentos a la luz de tres ejes básicos de debate: el método, el modelo de ciencia y la disputa en torno al lugar que debe ocupar la ciencia histórica o la sociología en la clasificación de las ciencias sociales. Para ello será preciso abandonar toda pretensión de reconstruir el debate a partir de una lógica gremial o corporativa; no se trata de juzgar a un clásico por los excesos no cometidos en el presente, y mucho menos de revitalizar una disputa (sociólogos versus

1. Véanse, por ejemplo, la Revue Historique, la Revue des Questions Historiques, el Bulletin de la Société d'Histoire Moderne. Y después, entre las publicaciones filosóficas y sociológicas francesas, la Revue Internationale de Sociologie, la Revue de Methaphisique et de Morale, donde Simiand publicó sus primeras reseñas, el Bulletin de la Société Française de Philosophie ydos de las revistas más innovadoras del momento: l'Année Sociologique y la Revue de Synthèse Historique. 
historiadores) que hoy día no persiste bajo la forma de dos comunidades en pugna. $^{2}$

Si en efecto son relevantes las situaciones de los comienzos no es por una cuestión relacionada con el culto al origen o la arqueología disciplinar, sino por ser indicadoras de los momentos más propensos a explicitar los principios de construcción que caracterizan a una ciencia (Bourdieu y Passeron, 1968: 53). En cierto sentido, la polémica entre Simiand y Seignobos representa un momento privilegiado para ilustrar el modo en que dos comunidades de investigación, cada una de ellas desigualmente equipadas en términos de capital simbólico e institucional, ${ }^{3}$ luchan entre sí para imponer los principios de especificidad de sus objetos, así como para proclamar su papel rector en el concierto de las ciencias sociales de la universidad republicana.

Lo que plantea este artículo es que la disputa iniciada en 1903, que opone dos candidaturas a la hegemonía del campo de las ciencias sociales, marca un momento ineludible en el espacio de las ciencias sociales e históricas francesas. Ello es así por varios motivos, pero sobre todo por el alcance que ciertas reflexiones de Simiand tuvieron para el debate posterior sobre la explicación causal en ciencias sociales. En ella se anunciaba, casi de manera primigenia, la necesidad de complejizar la explicación histórica e introducir la cuestión acerca de las distintas categorías causales que pueden existir con respecto al cambio social.

Obviamente, el debate no trajo consigo la transformación inmediata de la investigación histórica: hubo una corriente de historiadores que continuó organizando sus trabajos en función del tiempo cronológico y los marcos clasificatorios denunciados por los sociólogos, pero también hubo un número importante de investigadores que no pudo permanecer indiferente ante la ampliación de problemáticas que empezaron a insinuarse desde los márgenes del campo historiográfico y las trincheras sociológicas: tratamientos formales de datos, periodización de larga duración, descripciones multidimensionales de áreas de la cultura, etcétera.

El artículo que presentamos aquí es por tanto un homenaje a esta polémica, en parte desconocida por numerosos investigadores en ciencias sociales, o

2. Ahora bien, que tales disciplinas no estén en pugna tampoco significa que sean plenamente indiscernibles. J. H. Goldthorpe (1991: 211-215), por ejemplo, abrió la posibilidad de una diferenciación nueva entre ellas, motivada por el distinto tipo de evidencia que generan las dos disciplinas. Enfoques diversos, que hablan de convergencia y no de acuerdo o programa, en Passeron (1991), Revel (1979) o Burke (1992: 20).

3. Esto es así porque la historia, en ese momento, es un dispositivo disciplinar saturado de capital simbólico. Acumula en su seno un gran número de recursos objetivos, ya sea en forma de instituciones académicas (facultades, departamentos de historia, inserción en los planes de estudio en la educación secundaria y primaria), ya sea en forma de redes para-académicas (congresos, sociedades de historia, revistas, etcétera). Asimismo, gozaba de un importante capital simbólico en el conjunto de las instituciones políticas republicanas. La sociología, por el contrario, apenas tenía presencia institucional. Véanse Karady (1976: 267-311; 1979: 49-82), Réberioux (1983: 219-230), Besnard (1986: 27-35), Noiriel (1990: 58-85), Keylor (1975) y Carbonell (1976). 
cuyo conocimiento — en el mejor de los casos — se limita solamente al ataque realizado en 1903 por parte de Simiand, ignorando así que aquella intervención trajo consigo una serie de conferencias y recensiones críticas cuya riqueza epistemológicas no se debería desdeñar.

En adelante, centraremos la atención en el análisis de los argumentos en disputa. Para ello es preciso comenzar con una cronología mínima del debate: ¿dónde y cuándo tuvo lugar? ¿Quiénes fueron sus principales interlocutores? ¿Qué instituciones lo promovieron y qué retos se disputaban?

\section{Delimitando el terreno: antecedentes y cronología del debate}

Para poder entender las cuestiones que se formulan en el debate, es preciso ponerlas en relación con una serie de problemáticas que ya comenzaron a plantearse en el trascurso de los años precedentes.

Uno de tales precedentes se encuentra en la polémica suscitada en Francia por la obra de Paul Lacombe De l'histoire considérée comme science. Publicada inicialmente en 1894, la obra prefigura algunas cuestiones que serán objeto de disputa entre la sociología durkheimiana y la historia historizante. Abreviando en exceso, se puede resumir su crítica de la siguiente manera: el saber histórico no debe privilegiar los hechos individuales. Si solo hay ciencia de lo general, la historia erudita no se puede asemejar al discurso científico; se identifica, a lo sumo, con un saber erudito, pero no con una ciencia en sentido estricto, ya que sus causas explicativas siguen identificándose con hechos individuales. Así pues, reconstruye el pasado histórico a partir del encadenamiento cronológico de causas y efectos, según el modelo de los móviles psicológicos de los individuos (Lacombe, 1894: 12).

Para Lacombe, el acontecimiento es solo el punto de partida del análisis histórico, una causa eficiente cuya única finalidad «es dar la ocasión de que lo general» (verdadero objeto de la futura ciencia histórica) «se manifieste» (ibíd.: 10-11). De ahí la reivindicación de un horizonte sociológico para la ciencia histórica (Réberioux, 1983: 219), algo que también subrayaba el filósofo Louis Bourdeau en su libro L'Histoire et les historiens, essai critique sur l'histoire considérée comme une science positive (1888), donde se indicaban importantes aserciones en favor de la cuantificación y el análisis de las propiedades distributivas de los datos (Bourdeau, 1888: 131-13). Así, el valor científico de la historia, su alcance explicativo, debía depender solo de su capacidad de integrar la estadística y mutarse en una historia cuantitativa (Léroux, 1998: 62). La tendencia por lo individual, antaño objeto de la disciplina histórica, representaba el tics que debía ser desterrado del sistema de evidencias procedimentales de los historiadores, al igual que su predilección por la dimensión política del devenir histórico. La desaparición de tales elementos constituía el requisito básico para el desarrollo de la objetividad en la ciencia histórica.

Como se ve, en ambos autores subyace el mismo interrogante: ¿cómo y en qué condiciones el trabajo histórico puede convertirse en ciencia? Y aunque la respuesta a tales cuestiones no sea del todo idéntica, en los dos casos se 
percibe el mismo objeto de crítica, si bien es cierto que tales antecedentes no alcanzaron ni el influjo ni la rigurosidad conceptual desarrollada por Simiand. Posiblemente, porque carecían del reconocimiento institucional que suministra la existencia de un emplazamiento disciplinar: aquellas primeras críticas no pasaban de ser reflexiones «marginales» o "periféricas» en el establishment historiográfico francés. ${ }^{4}$

Críticas e interrogantes similares empezaron a desarrollarse paralelamente en otras latitudes, especialmente en Austria y Alemania, donde la disputa sobre el método (Der Methodenstreit) comenzó a tomar forma a raíz de la publicación en 1871 del libro de Carl Menger Grundsätze der Volkswirtschaftslehre. Este texto, centrado en cuestiones de tipo económico, fue sin embargo el detonante de una fructífera discusión sobre el método de las ciencias sociales en el ámbito académico germanoparlante (Sevillano, 2018: 195). Inspirado en la necesidad de fundar una ciencia económica abstracta, Menger (1883) se opuso al historicismo practicado por la Historische Schule der Nationalökonomie de Gustav Schmoller, quien defendía la necesidad de investigar las regularidades en los fenómenos económicos como «leyes históricas», o lo que es lo mismo, que no era posible establecer una ciencia económica abstracta de validez general más allá del análisis del contexto particular de tiempo y de lugar (Schmoller, 1883: 239).

Todo ello suscitó una avivada discusión en torno a las diferencias entre la investigación económica teórica y la aplicada. Pero también contribuyó a renovar el interés por la cuestión de las diferencias metodológicas entre la historia, la economía y las ciencias naturales, siendo de vital importancia la cuestión del método y la particularidad de las ciencias sociales. En esa línea cabe mencionar los trabajos de W. Dilthey, y en especial su célebre Einletung in die Geisteswissenschaften (1883), donde se trataba de dotar a la disciplina histórica de un campo de racionalidad propio, diferente, si se quiere, de los supuestos y las estrategias explicativas proporcionados por el método de las ciencias naturales. Historia y naturaleza denotaban así dos realidades diversas: el método histórico debía consistir no ya en buscar las conexiones necesarias de los fenómenos, como sucede en las ciencias naturales, sino en rastrear el conjunto de relaciones accidentales que acontecen en el pasado histórico. Se trataba, pues, de un método interpretativo: reconstruir las vivencias de los sujetos con el objeto de que la comprensión (Verstehen) de su psicología permita entender las razones de los acontecimientos históricos.

4. Tanto Lacombe como Bourdeau representan posiciones marginales en el conjunto de la comunidad historiográfica. En el primer caso la publicación de su obra marca un rumbo ecléctico y experimental, mitad sociología, mitad ciencia histórica. Sus propuestas solo eran pertinentes para un público propenso al eclecticismo y las propuestas experimentales. De ahí su relación con H. Berr y la Revue de Synthèse Historique, de la cual fue colaborador asiduo desde el año de su fundación. En cuanto a Bourdeau, la distancia es mayor si cabe. De hecho, ni siquiera formaba parte de la comunidad de historiadores. Se trataba de un filósofo, lo que le situaba en una posición demasiado externa como para influir en las dinámicas intelectuales de los historiadores. Más información en Carbonell (1978: 180-182), Léroux (1998: 52-75). 
Esta reflexión tuvo cierta influencia entre los neokantianos de la escuela de Baden, sobre todo en Wihelm Windelband y su discípulo Heinrich Rickert, quienes profundizaron en la pista inaugurada por Dilthey y propiciaron un desarrollo más perfilado de la distinción entre ciencias nomotéticas y ciencias ideográficas, incluyendo a la propia historiografía entre estas últimas, en tanto que "ciencia de lo individual, de lo que solo se produce una vez" (Rickert, 1901: 123). Pero fue sin duda la polémica de la Kulturgeschichte la que más repercusión tuvo en Francia y la que más similitudes puede tener con la disputa del método tal como se planteó en el hexágono francés. Todo comenzó con la publicación, en 1900, de la obra de Karl Gotthard Lamprecht Die Kulturhistorische Methode. En ella el historiador alemán arremetía contra la tendencia, tan común en la historiografía de la época, de limitar el análisis histórico a los aspectos descriptivos y la reconstrucción de lo individual. Frente a las obsesiones típicas de los historiadores rankeanos, centrados en la dimensión política del pasado y la biografía de las grandes personalidades, Lamprecht oponía el estudio de las llamadas «fuerzas psicológicas», entendiendo por esto una forma de historia colectiva centrada en la reconstrucción empírica del cambio de la conducta humana en el largo plazo. El objetivo de esta historia era edificar un análisis comparativo en el que se pusiera de manifiesto el cambio de la constitución psíquica de los sujetos en un proceso histórico observable, lo cual exigía integrar conocimientos (enfoques, objetos de investigación) procedentes de diversas disciplinas, como la etnografía, la geografía y la psicología social. ${ }^{5}$

Ciertamente el enfoque de Lamprecht no tuvo mucha prédica en Alemania, ${ }^{6}$ pero sí cosechó una difusión relevante al otro lado del Rin. Las propuestas de la Kulturgeschichte fueron analizadas y debatidas en las nuevas publicaciones francesas. Pero no para aceptarlas tal cual, sino para digerirlas y reconsiderar en ellas lo positivo que podía tener la psicología histórica en el análisis del desarrollo social (Berr, 1900: 6). El mismo H. Berr, al preguntarse por la evolución de la teoría de la historia en Alemania, ${ }^{7}$ reivindicaba lo que había de sugestivo y fascinante en la obra de Lamprecht, al cual le brindó la posibilidad de escribir en el primer número de la Revue de Synthèse Historique. ${ }^{8}$ Su crítica de la historiografía alemana, la tendencia de esta última a conceder un papel desorbitado a las personalidades históricas y a sobredimensionar la actividad política, ${ }^{9}$ llevó a Lamprecht a elaborar un tipo de historiografía centrada en la dimensión colectiva de la realidad pasada, lo cual hizo que su obra suscitase una atención especial en la polémica sobre el método histórico en Francia. Tales cuestiones funcionaron como un depósito de recursos intelectuales, un ámbito desde el que los historiadores y los sociólogos franceses

5. Sobre el programa del Instituto de Historia Cultural y Universal fundado por Lamprecht y las relaciones de la Kulturhistorische con otras disciplinas, véase Weller (2010: 227-267).

6. El propio Lamprecht admite la animadversión que suscitaba su propuesta entre los historiadores alemanes. Véase Lamprecht (1900: 26-27).

7. «Notes, questions et discussions» (1905: 369-372).

8. Véase Lamprecht (1900: 21-27).

9. Véase Lamprecht (1900: 26). 
ensayaron sus propias formulaciones a partir de la reapropiación creativa de las problemáticas importadas, ${ }^{10}$ articulando los puntos de vista heredados, pero modificando también sus acentos, añadiendo innovaciones suscitadas por las dinámicas y las tradiciones intelectuales francesas.

Hasta aquí los antecedentes inmediatos. Sin embargo, el pistoletazo de salida de la polémica que nos interesa debería situarse en 1901, con la publicación, por parte de Seignobos, de su libro La méthode historique appliquée aux sciences sociales. Este texto se dividía en dos partes. La primera se dedicaba a presentar las directrices metodológicas que guían la práctica de los historiadores. Se trataba de reiterar las mismas precauciones que Seignobos y Langlois habían indicado en su manual Introduction aux études historiques, de 1898. La segunda, en cambio, planteaba cuestiones más problemáticas, ya que se proclamaba el papel rector del saber histórico en el conjunto de las ciencias sociales. En pocas palabras, la historia era para Seignobos la disciplina que debía guiar al resto de las ciencias sociales, dado que es ella la que centra su atención en la perspectiva diacrónica de los fenómenos. Aunque Seignobos admita la legitimidad de las ciencias sociales, les adjudica una posición auxiliar con respecto al papel de la historia en la lectura del cambio social.

Semejante posición constituye el detonante del debate, el momento en el cual los jóvenes durkheimianos se sienten directamente agraviados, ya que consideran que la propuesta del historiador francés no solo reduce la investigación histórica a un procedimiento de tipo descriptivo, sino que también dota de su carácter heurístico al resto de las ciencias sociales. Fruto de aquella publicación fueron las recensiones críticas de algunos investigadores conocidos ${ }^{11}$, cuyas opiniones coincidían en un tema recurrente: la necesidad de pensar un modelo de ciencia objetiva (comparativa, no ideográfica) para el estudio de las representaciones sociales, a las cuales el planteamiento de Seignobos había reducido a estados de naturaleza subjetiva. Cierto es que este debate no fue muy diferente del que se había producido en lugares como la Revue de Synthése Historique. Historiadores tan dispares como Alexandru Dimitrie Xénopol o Paul Lacombe habían protagonizado sendas discusiones relacionadas con la naturaleza del conocimiento histórico y la posibilidad de establecer leyes en la historia. Lacombe cuestionaba la distinción del historiador rumano entre "hechos coexistentes» y "hechos sucesivos», ya que semejante teoría hacía depender el objeto formal de la historia (la causalidad en la sucesión, la causalidad de los hechos individualizados por el tiempo) de los presupuestos de un saber histórico centrado en la dimensión política y episódica de los acontecimientos (Lacombe, 1900: 33).

10. El ejemplo emblemático es la propuesta de «síntesis histórica» ofrecida por H. Berr. Su programa es en cierto modo un intento de conjugar de manera creativa los diversos aportes suscitados por la Kulturgeschichte y el trabajo de la sociología. Véase Berr (1900: 1-8).

11. De las múltiples recensiones, cabe recordar la de Durkheim en L'Année Sociologique (1902: 123-127), la de H. Berr (1902: 293-302) en la Revue de Synthèse Historique y también la de Dominique Parodi (1899: 142-145), esta última centrada en otro libro anterior de divulgación metodológica de Seignobos. 
Tales antecedentes constituyen el marco de reflexión en que va a producirse la polémica entre Simiand y Seignobos. Sin embargo, el momento inmediato de inflexión, el que suscitó el interés y la concurrencia de varias instituciones intelectuales se producía el 3 de enero de 1903, a raíz de una conferencia ofrecida por Simiand en la Société d'Histoire Moderne. Aquella comunicación tenía un escueto e inocente título, "Méthode historique et Science Sociale», pero en realidad se trataba de una respuesta bastante dura (aunque desigual) ${ }^{12}$ a las obras de P. Lacombe (De l'histoire considerée comme science) y de Ch. Seignobos (La méthode historique appliquée aux sciences sociales), y en especial al pesimismo expresado por este último en su análisis de las limitaciones cognitivas de la ciencia histórica, las cuales, entendía, eran extrapolables a cualquier iniciativa (sociología, economía, etnología) que tratase de aprehender lo social. En ese momento, la conferencia no pasó desapercibida: posiblemente, porque aquella intervención se pronunció en el seno de la Société d'Histoire Moderne, lo que aseguraba la resonancia del discurso durkheimiano en uno de los principales bastiones de la comunidad historiográfica. ${ }^{13}$ Acto seguido, la comunicación se publicaba en la revista de H. Berr, la Revue de Synthèse Historique, ${ }^{14}$ a lo que siguió otra cascada de recensiones críticas en el trascurso de ese mismo año, esta vez en publicaciones propensas a la comunicación interdisciplinar, ${ }^{15}$ salvo la excepción significativa de la Revue Historique, que no publicó texto alguno relacionado con esta célebre disputa. ${ }^{16}$

Pese a ello, la polémica estaba servida. Los historiadores habían sido interpelados a través de la crítica de uno de sus más eminentes representantes, que por aquel entonces ocupaba un puesto como profesor en La Sorbona. Tal ataque sin embargo no encontró una respuesta inmediata por parte de Seignobos, lo que provocó un cierto abandono de la polémica hasta el año 1906, fecha

12. Desigual porque la obra de Lacombe, pese a aparecer rotulada en el subtítulo, apenas es analizada, más allá de ciertos elogios o referencias de pasada. El peso de la atención se lo lleva la obra de Seignobos.

13. La Société d'Histoire Moderne surge en 1901 con el objeto de difundir y promover el debate entre los historiadores. En aquella comunicación participó un elenco variado de personalidades, algunas tan relevantes como G. Bloch (padre del famoso M. Bloch), H. Berr, H. Hauser, Ch. Seignobos o el filósofo de las ciencias G. Milhaud. Un resumen en el Bulletin de la Société d'Histoire Moderne (1903: 73-77).

14. F. Simiand publica su conferencia en la Revue de Synthèse Historique. Pero debido a la extensión del texto la revista decide publicarlo en forma de dos extensos artículos, de los cuales el primero aparece en febrero de 1903 (1-22) y el segundo en abril de ese mismo año (129-157).

15. En L'Année Sociologique se puede encontrar una reseña del mismo en Bouglé (1904: 148151). Por su parte, el historiador P. Mantoux (1903: 121-127) hizo una larga recensión crítica de las posiciones expresadas en el texto de Simiand.

16. Rastreando los índices de la Revue Historique desde 1903 a 1909, no hemos encontrado ni un solo texto dedicado al tema. ¿¿Por qué una revista de esta relevancia no se hace eco de semejante debate? Pero, sobre todo, ¿por qué no lo hace cuando uno de sus colaboradores habituales (Ch. Seignobos) es el principal imputado en la disputa abierta por Simiand? Sea cual sea la respuesta, lo cierto es que este silencio es significativo por sí solo. El conservadurismo metodológico cosechado en el campo historiográfico contrasta fuertemente con el progresismo político expresado por sus miembros en la defensa del capitán Dreyfus. 
en la cual Simiand prosigue sus argumentos críticos en una conferencia ( $\mathrm{La}$ causalité en histoire») pronunciada en la Société Française de Philosophie. ${ }^{17}$

Es ahí cuando comienza la segunda etapa del debate (1906-1908), que transita de la Société d'Histoire Moderne, espacio dominado por historiadores, a la Société Française de Philosophie, lugar de raigambre filosófica (como el origen de los durkheimianos) pero propenso al debate y al intercambio interdisciplinar, especialmente cuando los temas considerados concernían a las ciencias o a la reflexión epistemológica. Tal etapa se compone a su vez de tres conferencias: la primera de ellas constituye el enfoque más propositivo de Simiand. En ella el sociólogo francés ofrece una serie de pautas sobre las cuales debe asentarse todo conocimiento que pretenda aspirar a ofrecer explicaciones objetivas. Después, combina la exposición de tales pautas con el análisis de algunos pasajes de las obras de Ernst Bernheim y de Seignobos, a fin de advertir en ellas un tipo de construcción argumental basada en el uso vulgar de la idea de causalidad.

De ese modo, la pelota estaba de nuevo en el tejado de los historiadores, con la diferencia de que ahora la ofensiva ejecutada por Simiand no dejó indiferente al recién nombrado catedrático de "método histórico» de La Sorbona. ${ }^{18}$ Un hombre de su posición académica, titular de una cátedra en la facultad más prestigiosa de Francia, no podía rehuir por mucho más tiempo la polémica y estaba obligado a defenderse de la retahíla de acusaciones lanzadas desde las trincheras de la periferia sociológica. El resultado fue la conferencia pronunciada el 30 de mayo de 1907, titulada «Les conditions pratiques dans la recherche des causes dans le travail historique». Como su propio nombre indica, esta conferencia es una respuesta que procede de la práctica histórica. No es una respuesta de un teórico, sino de alguien que conoce de primera mano las limitaciones propias de la investigación histórica. En ella Seignobos recoge las apreciaciones esgrimidas por Simiand y trata de neutralizarlas apelando a las condiciones empíricas (a menudo exiguas y desfavorables) en las que se desarrolla la investigación de los historiadores. Si la ciencia histórica, dice, revela limitaciones es porque la práctica investigativa se desarrolla en condiciones profundamente limitadas (documentos redactados en lengua vulgar, documentos o series de documentos incompletos, referencias no analíticas a hechos particulares, etcétera). Así pues, no cabe plantear un modelo de explicación histórica basado en los nexos que se infieren de la correlación numérica de variables. Ello es así porque, a diferencia de la sociología, que trabaja con datos relativos al plano formal de los fenómenos, en historia no se dispone más que de materiales vulgares e incompletos, cuyos análisis permiten únicamente la búsqueda de una causalidad particular, de los fenómenos psicológicos que dirigen un acto (Seignobos, 1907: 600).

17. Aunque no sea una respuesta a F. Simiand lo cierto es que Ch. Seignobos participa en una conferencia dedicada a las relaciones entre historia y sociología. Dicha conferencia tuvo lugar en la Ecole des Hautes Etudes Sociales, junto al sociólogo C. Bouglé. Los resúmenes de ambas conferencias pueden encontrarse en la Revue Internationale de Sociologie, concretamente en Pournin (1904: 161-167).

18. La cátedra de Método Histórico en La Sorbona es ocupada por Seignobos en 1907. 
Por esta razón, el público asistente encuentra esta conferencia problemática, tal como se desprende del debate que clausura la sesión, donde Simiand y otros historiadores no dudan en advertir las desalentadoras implicaciones que se derivan del enfoque de Seignobos. Tal es el caso de Gustav Glotz o P. Lacombe, quienes recriminan la falsa modestia de sus argumentos y su disimulado desprecio ante formas alternativas de investigación histórica de carácter comparativo. O bien, la postura de André Lalande, que con un tono jocoso - pero tremendamente cruel — denuncia las inconsistencias metodológicas de los historiadores apelando a su escasa formación en materia de filosofía y estudios sociales.

Pero el debate no acaba aquí: existe una última cita en la que se volvió a requerir la presencia de Seignobos, esta vez para discutir junto a otros especialistas (entre los cuales se encuentra Émile Durkheim) el papel que desempeñan las representaciones colectivas («lo inconsciente») en los fenómenos sociales. Dicha conferencia tuvo lugar el 28 de mayo de 1908 y llevaba por título "L'inconnu et l'inconscient en histoire». Los interrogantes que se planteaban eran claros: ¿qué lugar ocupa «lo inconsciente» en los fenómenos sociales?, ¿̨se puede aceptar un mecanismo explicativo que no se agote en las razones que los agentes atribuyen a los acontecimientos?, ¿es posible admitir otras causas históricas? Para responder a estas preguntas, el historiador retoma los argumentos esgrimidos en el año anterior, si bien es cierto que ahora, exhortado tal vez por las cuestiones incisivas de Durkheim, el debate se desplazó al plano de lo inconsciente en historia, al tiempo que se suscitaban interesantes cuestiones acerca de los límites que subyacen al modelo de la explicación intencional defendido por Seignobos.

Sea como fuere, esta conferencia presenta un cruce de acusaciones confusas. Todo sucede como si hubiera una sensación de confusión en el ambiente, como si en ciertas ocasiones no se acabase de tener claro si lo que Seignobos achaca a los sociólogos se corresponde en realidad con lo que estos planteaban en sus trabajos. De hecho, esta misma sensación es suscrita por el propio Durkheim en un momento dado de la conversación: cuando replica al historiador el malentendido en el que este último se encuentra al entablar paralelismos entre las realidades colectivas de los sociólogos y las realidades supraindividuales de los historiadores alemanes (Seignobos, 1908: 244).

En las páginas siguientes trataremos de poner al descubierto las claves de esta célebre disputa. Para ello se pasará revista a las principales diferencias que separan a los autores en materia de reflexión epistemológica, haciendo especial hincapié en las cuestiones de método, de ciencia y en la posición que debe ocupar la ciencia histórica o la sociología en el concierto de las ciencias sociales.

\section{Un debate con estilos argumentales diferentes}

Antes de abordar tales cuestiones, conviene recordar algunos aspectos referidos a los presupuestos del debate. Así, lo primero que llama la atención, sin entrar aún a considerar los argumentos, es la disparidad de estilos que se desprenden 
de las intervenciones. El caso de Simiand es quizá el más palpable. Interesado por las inquietudes metodológicas de los historiadores, el sociólogo decide contribuir al debate cuestionando la capacidad de la historiografía para ser un conocimiento científico. En ella, dice, el razonamiento metodológico no responde a ninguna de las exigencias del saber científico, sobre todo en el plano de la explicación causal, donde se manifiesta una propensión clara a vincular los criterios explicativos con modelos de agencia de carácter intencional. La suya, por tanto, es una intervención que responde a exigencias de naturaleza estrictamente epistemológica; por eso no duda en movilizar una serie de argumentos que tratan de mostrar la incoherencia entre la codificación metodológica de los historiadores y las exigencias objetivas de la ciencia (Simiand, 1903: 139). Pese a ello, el joven sociólogo muestra su esperanza en la renovación del saber histórico; su disputa no es un simple ajuste de cuentas; tras el tono y la virulencia del ataque, se perfila una invitación a la reforma tras demostrar las insuficiencias que aquejan a la práctica investigativa de los historiadores (ibíd.: 168).

En este sentido, es preciso abandonar — dirá - los obstáculos que impiden la conversión del saber histórico en un terreno próximo a las problemáticas sociológicas. Tres obstáculos, o tres ídolos, que dan por supuesto el sistema de jerarquías implícito (prioridad de las fuentes político-administrativas, prioridad del estudio de la dinámica centralizadora del poder monárquico) que estaba en la base de las compilaciones documentales realizadas por los archivistas del Antiguo Régimen: ${ }^{19}$

1. El ídolo político: la tendencia habitual entre los historiadores de la época a conferir un papel privilegiado a los hechos políticos. Con ello la historiografía corre el riesgo de quedar reocupada por dispositivos ideológicos implícitos, al fijar su práctica de investigación en los términos con que vienen calificados en los propios documentos, sin realizar un trabajo previo de objetivación. Todo ello hace que los marcos clasificatorios queden ordenados por criterios tan poco científicos como los reinados o las batallas, que reciben su legitimidad de las convenciones delimitadas en otras prácticas sociales (burocráticas, políticas, morales, etcétera), y no de una elaboración científica y reflexiva.

2. El ídolo individual: es decir, el hábito de ordenar la investigación histórica en torno a un individuo o un grupo de individuos particulares. Así, en lugar de centrar la mirada en la estructura social, el historiador tratará de explicar los hechos atendiendo al influjo que ejercen los individuos situados en la cúspide de la estructura social. De ahí el éxito de las biografías y las hagiografías, un género en boga en la producción histórica del momento.

3. El ídolo cronológico: la costumbre de perderse en el estudio de los orígenes, en lugar de analizar el tipo normal o los hechos recurrentes que aparecen en la

19. Nos referimos a las grandes empresas archivísticas financiadas por la corona francesa en su batalla contra la Santa Sede y los parlamentos: la congregación benedictina de Saint-Maur, la Académie des Inscriptions et Belles-Lettres y el Cabinet de Chartes. Más información en Barret-Kriegel (1988) y Domínguez (2019) 
sociedad. Todo sucede como si la historiografía del siglo xIx hubiera identificado la dimensión temporal con la cronología lineal de la experiencia vivida, desterrando así toda posibilidad de experimentar y comprender el pasado a partir de duraciones que sobrepasan la escala de la experiencia vivida de los agentes.

Pese a ello, el objetivo no consiste en rechazar la disciplina histórica en cuanto tal; el objetivo más bien consiste en ubicar el trabajo histórico en el conjunto de un espacio intelectual regulado por las reglas del método sociológico. $\mathrm{He}$ aquí el argumento: por un lado, Simiand admite la variedad de los fenómenos (jurídicos, económicos, religiosos, etcétera) estudiados por las ciencias sociales, pero, por otro, reconoce el hecho de que todos ellos comparten el carácter esencial de ser «hechos sociales», tal como define el término Durkheim (1895: 18-19). Así, partiendo de esta igualación, Simiand deduce una consecuencia relevante: si las ciencias humanas poseen un objeto común (el carácter «social» de las realidades humanas) sus prácticas particulares (históricas, económicas, etnológicas, etcétera) deben ser intercambiables, a fin de que todas ellas estén en condiciones de intercambiar y evaluar sus resultados de acuerdo a una epistemología común (Noiriel, 2003: 52).

Tal es el objetivo de la sociología durkheimiana: concebir una ciencia social unitaria, ${ }^{20}$ para lo cual es necesario destituir la soberanía metodológica de las ciencias sociales e imponer en sus agendas el punto de vista sociológico. Durkheim y Fauconnet (1903: 148) expresan esta misma idea utilizando un lenguaje más ameno y apacible. Las ciencias sociales, dicen, aportan un importante suministro de conocimientos empíricos, en algunos casos lo suficientemente adecuados como para explotarse de acuerdo a las exigencias del método sociológico. Para ello es preciso intervenir las agendas de los investigadores. La tarea de la sociología debe consistir en ayudarles a ver las interdependencias que existen entre ellas, así como a examinar sus resultados a la luz del establecimiento de las regularidades sociales (ibíd.: 159). En una palabra, la sociología debe terminar con la dispersión de las ciencias sociales, de modo que estas últimas acaben transformándose "en ramas o modalidades particulares de una ciencia social que se rige por las reglas del método sociológico».

Se entiende así el uso que los durkheimianos hacen de la historia. Tal disciplina es la que proporciona el campo de experimentación posible de la sociología, la única, por decirlo así, capaz de suministrar los materiales empíricos con los cuales se pueden desarrollar las inducciones generales del enfoque sociológico. ${ }^{21}$ De ese modo, la sociología era contemplada como una construcción inductiva que opera sobre hechos recurrentes y que aspira, precisamente

20. Sirva como pista el título de la intervención de Simiand en 1903. Allí se habla en todo momento en singular: «Método histórico y ciencia social». No se dice «ciencias sociales» en plural, sino «ciencia social» en singular. Véase Revel (1999: 391).

21. Este argumento ya se puede identificar en H. Spencer, quien sostenía que la función de la ciencia histórica debía consistir en suministrar las piedras (heaps of stones) para la construcción del edificio sociológico. Véase Spencer (1859: 29). 
por ello, a construir leyes a largo plazo según el modelo de una física social. ${ }^{22}$ Por eso Durkheim y Simiand cuestionan al saber histórico de su época: este último, como admitió más tarde Collingwood (1952: 152-159), se dedicó a la primera parte del programa positivista al establecimiento metódico de los hechos, lo cual trajo consigo el desarrollo de una gran cantidad de fuentes y herramientas de investigación documental; pero, al centrar su atención en esas tareas, la historiografía desestimó el otro requisito del programa positivista, el establecimiento de leyes y regularidades entre los hechos. Dicha tarea empezó a tomar cuerpo en el imaginario colectivo de los primeros sociólogos, quienes trataban de presentar su trabajo intelectual como una superación científica del trabajo acometido por los historiadores, al pensar en un sentido nomológico los hechos que el historiador había pensado en términos empíricos (ibíd.: 153).

Tal es la naturaleza de los argumentos durkheimianos. Su crítica, como decíamos, no es un simple ajuste de cuentas, es ante todo un llamamiento a «la renovación integral de la ciencia histórica». Queda por saber, sin embargo, cuál será la traducción que puede adoptar una fórmula de tales características: ¿significa, como se pregunta Ramón Ramos (1999: 105), la desaparición de la ciencia histórica por la «sociología dinámica» o se trata más bien de la constitución de una disciplina común, producto de la fusión pacífica de los dos saberes? $\mathrm{O}$ tercera posibilidad, ¿se refiere a la coexistencia de ambas disciplinas como saberes autónomos, aunque con objetos, métodos y procedimientos similares, siendo su diferencia solo de grado?

La solución a estas cuestiones no está del todo clara, ya que los textos durkheimianos apuntan simultáneamente a todas esas direcciones. ${ }^{23}$ La tercera posibilidad refleja sin duda la evolución de las dos disciplinas en la segunda mitad del siglo xx. Sin embargo, no es seguro que esa fuese la idea de "coordinación» barajada por Durkheim; su proyecto parecía más bien decantarse por la primera opción, o al menos por una existencia fagocitada de la historia. Véase por ejemplo el intercambio de servicios que propone a los historiadores: su función debía consistir, en primer lugar, en la crítica y la compilación de hechos a través del método histórico, después transmitir tales hechos a los sociólogos, quienes decidirían cuáles son significativos y cuáles no lo son. Tal esquema, dice Durkheim, debería ir modificándose con el tiempo, a medida que los historiadores interioricen las hipótesis y las problematizaciones que deben prevalecer en la selección de materiales. Finalmente, la cooperación entre ambas disciplinas haría posible que «los historiadores se convirtieran por fin en sociólogos» (Durkheim, 1888a: 46-47; 1909: 283; 1898a: III-IV).

En este sentido, la entente que plantea a los historiadores está muy lejos de sellar un acuerdo paritario entre las dos disciplinas (Borlandi, 2017: 95). Los

22. Sobre la diferencia entre labor historiográfica y tarea sociológica, véase Durkheim (1909: 284).

23. Aunque Durkheim dice que ambas disciplinas están condenadas a fundirse, no siempre está claro el modelo de integración que plantea. En ocasiones, parece defender una existencia pacífica entre iguales (Durkheim, 1888b: 31). Otras, sin embargo, apunta a una integración basada en la división jerarquizada del trabajo (Durkheim, 1909: 284). 
sociólogos ocupan siempre un papel rector: dirigen el proceso cognoscitivo desde sus inicios, decidiendo qué hipótesis son las que deben prevalecer y en qué dirección han de movilizarse (y supervisar) los recursos productivos (el trabajo recolector) de los historiadores. En otras palabras, en el programa de unificación esbozado por los durkheimianos, no hay una coexistencia armónica de disciplinas, sino una verdadera división interna del trabajo en el seno de las ciencias sociales. Traducido a lenguaje disciplinar, significa una pérdida de autonomía para la ciencia histórica, «al convertir a esta última en una disciplina comparativa supeditada a testar las hipótesis construidas en otros contextos enunciativos, al margen de ella» (Revel, 1999: 392).

Por su parte, el discurso de Seignobos mantiene un estilo defensivo. En él será difícil encontrar un argumento que consista en el despliegue de una epistemología coherente (Noiriel, 2003: 54). Seignobos carecía de las competencias filosóficas como para expresar su punto de vista en el mismo lenguaje en que se expresaba el joven sociólogo. Entre ambos se aprecia un registro de estilos diferentes: mientras Simiand utilizaba un lenguaje teórico y epistemológico, en Seignobos hallamos una retórica pragmática y atenta al sentido práctico del oficio (Seignobos, 1907: 592).

Naturalmente esto no invalida sus argumentos, pero sí refleja el hecho de que su defensa argumental oscila entre dos polos contradictorios (Noiriel, 2003: 55): por un lado, el posicionamiento público de un profesor universitario que acepta el hecho de que la disciplina histórica debe emular los protocolos de descripción utilizados por las ciencias (Seignobos, 1907: 592-593), y por otro, el argumento de un historiador de profesión, a quien no le queda más remedio que admitir la limitación de la ciencia histórica (no existen observaciones directas, solo por analogía) y la imperfección de los materiales con los que trabaja el historiador (documentos sin cuantificar, redactados en lenguaje vulgar, etcétera). No se trata, pues, de rebatir los argumentos en el plano de la reflexión filosófica. Su posición es clara: la historia no es una disciplina susceptible de aceptar las reglas que defiende la sociología; al contrario, se trata de una ciencia limitada. Por ello no duda ni un instante en concatenar una serie de argumentos encaminados a reflejar una posición cercana al empirismo, si bien es cierto que Seignobos no pronuncia esta palabra ni trata de que su intervención adopte la forma de una posición filosófica coherente.

Abordamos a continuación la cuestión relativa al método y el modelo de ciencia. ¿Cuáles son las posturas en disputa?

\section{El método en disputa: la historia será sociológica o no será}

\section{1. "Teorias sin hechos» 0 "hechos sin teoria»: el debate en torno al método}

Como se ha dicho, el tema central es la relación entre teoría y hechos históricos. Por supuesto, esta cuestión no se formula como tal en el trascurso del debate, pero existen múltiples argumentos que bien podrían insertarse dentro de esta problemática. 
a) Empezaremos por las objeciones de Seignobos, quien parece encontrar una justificación a sus ideas en las limitaciones del trabajo histórico y el tipo de materiales con los que trabaja el historiador. Tal limitación será la base desde la que articula su defensa frente al ataque de Simiand, al entender que este sociólogo plantea un corpus de procedimientos («definir en términos generales el efecto preciso») que no pueden aplicarse a los materiales históricos del pasado, defectuosos y limitados por naturaleza.

Su argumento toma como punto de partida la abstracción. Esta última, dice Seignobos, es la herramienta necesaria de la ciencia. Es la base desde la cual se establecen las conexiones regulares de los fenómenos. La abstracción, dice, es lo que nos permite trascender la singularidad empírica y operar sobre las determinaciones genéricas que les sobrevienen, a fin de promulgar hipótesis explicativas acerca de las relaciones que se producen entre las propiedades seleccionadas (Seignobos, 1907: 599).

No obstante, tal operación solo es factible en el ámbito de las ciencias experimentales, donde la observación de los fenómenos es el resultado de una experiencia provocada por la intervención artificial del investigador, pero no así en la ciencia histórica, que es un saber descriptivo (Seignobos: 1953: 4-5). Pero ¿por qué?, ¿qué hay de particular en la ciencia histórica para que cualquier intento de abstracción analítica sea tildado de ilusionismo o de falta de rigurosidad metodológica? El historiador no responde con claridad a esta pregunta: en ciertos momentos se remite a la imposibilidad de construir con los materiales históricos una correlación numérica de los fenómenos (Seignobos, 1907: 600). En otras, sin embargo, la repulsa parece derivarse de una oposición de fondo a los procedimientos de abstracción estadística. En efecto, el problema no es (o no es solo) la limitación de los materiales históricos; el problema es la noción misma de «hecho social». Para Seignobos, el «hecho social», tal como lo entiende Simiand, a la manera durkheimiana, es una abstracción construida de manera ilegítima (Seignobos, 1934: 21). Básicamente, porque los sociólogos descartan, en su categorización teórica, la dimensión psicológica y/o subjetiva de los hechos sociales. ${ }^{24}$ Así, en lugar de centrar el análisis en los motivos que los sujetos dan de sus acciones, los sociólogos optan por descifrar los documentos en función de criterios abstractos, convencidos de que la constitución de una sociología «científica» pasa por someter las «informaciones de base» a un tratamiento guiado por parámetros ausentes en los enunciados descriptivos de los agentes sociales. ${ }^{25}$

Así, se olvidan de aquello que, según Seignobos, hace inteligibles a los hechos sociales: la referencia a un estado psicológico-subjetivo. ${ }^{26}$ De ahí que,

24. Véase sobre todo el primer capítulo (¿Qué es un hecho social?) de Durkheim (1895).

25. Ideas similares, aunque desde una perspectiva más weberiana, parecen encontrarse en el sociólogo francés J.-C. Passeron (1991). A juicio de este, la categorización analítica construye una organización nueva de la observación histórica, en el sentido de que crea informaciones que no preexisten a la propia categorización, esto es, fenómenos empíricos («economía mundo», "evergetismo», "rutinización del carisma», etcétera) que no podrían haber sido «observados» sin el horizonte de inteligibilidad engendrado por tales teorías.

26. Esta es la razón de su crítica al «hecho social». Véase Seignobos (1901: 215). 
al preguntarse por la especificidad del trabajo histórico, el catedrático de La Sorbona reivindique abiertamente el papel de la analogía. El historiador, dice, no trabaja con objetos reales, trabaja con imágenes (representaciones) que él mismo ha formado por analogía con sus recuerdos, por medio de un estado de conciencia análogo al suyo (Seignobos, 1934: 21-23). El problema es que la imaginación (analogía) de la que habla Seignobos «no puede representarse más que actos individuales, a semejanza de aquellos que nos muestra físicamente la observación directa» (Seignobos y Langlois, 1898: 220). Así pues, si la imaginación se identifica con la percepción, si el historiador debe investir el documento con imágenes para poder representar los hechos de los que habla, entonces la ciencia histórica asume un horizonte de visibilidad limitado, ya que reduce todo cuanto está presente (y, por tanto, todo lo susceptible de ser historiado) a los fenómenos que han suscitado la percepción directa de uno o varios espectadores (Pomian, 1984: 7-36). Se entienden así las críticas realizadas por los durkheimianos a la disciplina histórica de su tiempo. En ella el investigador trabaja el documento desde la óptica de la esfera consciente de su productor, lo que significa que el discurso resultante, «al asumir el horizonte de experiencia cronológicamente registrable de los productores del documento", acepta un espacio argumental en el que los historiadores se ven obligados a narrar los hechos del pasado como si fuesen hechos biográficos, «imaginándose ser ellos mismos los testigos directos de aquello de lo que se habla» (Pomian, 1999: 173).

Nuestra imagen de la historia debiera al menos reproducir los rasgos esenciales de aquellos que tuvieron en sus mentes quienes presenciaron los acontecimientos pasados (...) El historiador, obligado no obstante a formarse imágenes de los hechos, debe asumir la responsabilidad de no hacerlo sino con los elementos exactos, de forma que se los represente tal como si hubiera podido presenciarlos él mismo. (Seignobos y Langlois, 1898: 223)

Así, para hacer inteligible la realidad del pasado el historiador debe investir el documento con imágenes subjetivas. Sin ello, dirá, no hay ciencia histórica en sentido estricto; todo lo más, un saber técnico y de apariencia científica, pero no un conocimiento capaz de expresar los caracteres concretos de las cosas (Seignobos, 1907: 600). En este sentido, la postura de Seignobos apenas se mueve un ápice del marco de comprensión inaugurado por el historicismo alemán, según el cual solo resultan historiables los fenómenos que son susceptibles de descomponerse en términos de acciones o actos reflexivos (Collingwood, 1952: 352).

De ahí la crítica del historiador francés a la sociología: su error, dice, no es haber ampliado el cerco de curiosidades temáticas; su error consiste en plantear un tipo de abstracción analítica (el «hecho social») cuya construcción no requiere la presencia de los nexos causales proporcionados por analogía con la psicología del sentido común (Vázquez García, 1989: 90). Todo sucede como si la ciencia histórica debiera edificarse sobre la experiencia vivida de los agentes. Lo único que hace posible que el pasado sea accesible a nuestra inteligencia es el hecho de referir un fenómeno a las representaciones que los 
actores hacen de su experiencia de la acción social. Más allá de esto no hay conocimiento histórico; ${ }^{27}$ tan solo un saber de apariencia abstracta cuya virtud (refiriéndose a la sociología) es dar la impresión de trabajar científicamente, cuando en realidad opera con representaciones que no tienen una relación evidente - fenomenológicamente aprehensible - con la experiencia de los actores (Seignobos, 1907: 600). Desde este punto de vista, todo sucede como si los conceptos fuesen reflejos de la realidad, de manera que cuanto más concretos sean los términos utilizados por el historiador más verdaderos (menos arbitrarios) serán los resultados expresados por el trabajo histórico (ibíd.: 622).

b) Por su parte, Simiand contrapone un enfoque distinto, al entender que esta crítica permite sentar las bases para pensar un concepto de ciencia social análogo al de las ciencias naturales (Simiand, 1903: 115). Su crítica es de sobra conocida: se trata del uso, problemático, que Seignobos realiza de los términos "psicológico» y «subjetivo", los cuales utiliza indistintamente para justificar el hecho de que toda representación psicológica se agota en una representación subjetiva. Para el sociólogo, cualquier fenómeno social viene acompañado de una representación psicológica; pero una cosa es decir esto, que nada tiene de problemático, y otra distinta es reducir lo psicológico — como hace Seignobos- a un fenómeno estrictamente subjetivo, dando a entender que la riqueza de los fenómenos mentales puede explicarse por medio de las representaciones conscientes que los actores hacen de su experiencia de la acción social. Así pues, si lo psicológico se reduce a «lo subjetivo» ${ }^{28}$ entonces lo psicológico parecería oponerse a «lo externo» y «lo objetivo». Pero ¿qué ocurriría si en lugar de reducir lo psicológico a «lo subjetivo», como plantea el historiador, se entendiera lo psicológico como un campo de problematicidad «objetivo», susceptible de albergar relaciones objetivas? (ibíd.: 119).

He aquí, sin duda, el eje argumental de Simiand. Pero también el significado más preciso de la primera regla metodológica planteada por Durkheim (1895: 29). Que los hechos sociales deban tratarse como cosas significa tan solo

27. Tanto es así que el propio Seignobos, al preguntarse por la posibilidad de la prehistoria, acaba por desechar la tentativa de hablar de ella en términos de "conocimiento histórico». Pues contradice uno de los preceptos básicos de la ciencia histórica del siglo XIX. Al no existir documentación escrita, el historiador, dice, no puede organizar ese pasado remoto mediante representaciones humanas (intenciones, acciones) (Seignobos, 1934: 11). Un argumento similar en Ranke, cuando señala que «hay que excluir radicalmente a esta (la prehistoria) de la historia porque contradice el principio histórico, el cual se funda en la investigación documental» (Ranke citado en Ortega, 1980: 145).

28. En sentido estricto, Seignobos no solo reduce lo psicológico a «lo subjetivo», sino que deriva también de ahí la existencia de un «orden de hechos específico» (los-hechos-de-la-concienciainterna). He aquí su razonamiento, que se inspira fuertemente en la filosofía contractualista y el individualismo metodológico: si todo acto individual comporta una parte de realidad psíquica, y la realidad social se descompone en realidades individuales, el análisis del hecho social pasa por una observación psicológica, en la medida en que las realidades individuales solo resultan accesibles mediante el estudio de los estados de conciencia y las representaciones internas que dirigen su conducta. Véase, sobre todo, Seignobos (1934: 5, 23-24). 
esto: considerar lo psicológico como un ámbito de análisis «objetivo», «externo» en cierto modo al individuo y por tanto susceptible de albergar operaciones analíticas construidas sobre la base de términos que "poco tienen en común con las vivencias que los sujetos hacen de su experiencia de la acción social».

A este respecto, conviene recordar un matiz importante, ya que esta regla podría dar a entender que la sociología se resuelve en un simple rechazo del enfoque psicológico en beneficio de un mecanicismo estadístico. Nada más lejos de la realidad. Basta una lectura de los textos durkheimianos para tomar conciencia de la centralidad que posee la dimensión psicológica en la constitución de la vida social. Todos ellos parten del supuesto de que la vida humana está hecha de representaciones mentales, de que el ser humano no puede estar en el mundo sin hacerse ideas o representaciones mentales; lo psicológico sería, en este sentido, el medio propio en el que se desarrollan y se reproducen los hechos sociales, el ámbito en el que la sociedad actúa en las conciencias individuales por medio de las representaciones colectivas. ${ }^{29}$ Así pues, no se trata de negar lo psicológico, sino de "poner de manifiesto, gracias a los mecanismos de cuantificación estadística, las múltiples dimensiones (el inconsciente social) de las que se compone el complejo fenómeno del psiquismo humano». Negar no tanto la psicología a secas, sino la psicofisiología y el introspeccionismo individual de la época, los cuales seguían reduciendo la vida psíquica o bien a un epifenómeno de las vibraciones celulares o bien a la conciencia «transparente» que los sujetos tienen de los estados mentales. ${ }^{30}$

Para ser honestos, la sociología de Durkheim no innova en este punto; simplemente toma nota de los avances producidos en la psicología de su tiempo y recapacita en torno a sus implicaciones para el análisis social. El descubrimiento de los "fenómenos subconscientes", tal como fueron señalados por Pierre Janet, ${ }^{31}$ un psicólogo normalien de la promoción de Durkheim, ejerció una importante influencia en el desarrollo del programa de investigación sociológica. El acierto de las doctrinas durkheimianas, como indica Laurent Mucchielli (1998: 197), consistió en retomar estas consideraciones y dotarlas de una formalización original por medio de la estadística. Por tanto, ninguna concesión a la idea de que los estados mentales se agotan en la conciencia que los sujetos tienen de sí (lo psicológico reducido a «lo subjetivo»), y mucho menos a la distinción clásica entre "ciencias naturales» y «ciencias del espíritu». En este punto, la sociología de Durkheim expresa su deuda con el modelo de las ciencias naturales y la defensa del monismo

29. Simiand había puesto de manifiesto esta misma idea en su crítica a la psicología del Homo economicus de los economistas liberales. Véase Simiand (1899: 461).

30. Véase la crítica de Durkheim a la psicofisiología de Huxley y Maudsley en «Représentations individuelles et représentations collectives» (1898b).

31. La hipótesis de un inconsciente social, que es trascendente respecto a las conciencias individuales y que sin embargo se refleja en su interior en forma de un orden autónomo (y normativo) de la realidad, debe mucho a las ideas de Pierre Janet en su libro L'automatisme psychologique (1889). Sobre la sociología durkheimiana como proyecto psicológico, véase Tapia Alberdi (2015: 307-314). 
metodológico. En su opinión, no cabe suponer dos realidades distintas, tal que estas últimas permitan diferentes accesos al campo de su racionalidad interna. Tanto el objeto de las ciencias naturales como el de las ciencias sociales deben compartir el mismo método de investigación científica. Un método basado en la búsqueda de regularidades abstractas que permitan formular "leyes generales», tanto en lo que se refiere al mundo de los hechos naturales como al mundo de los hechos sociales (Simiand, 1903: 137), esta última a través del método de las variaciones concomitantes.

Dejamos de lado la cuestión de si el razonamiento estadístico constituye una aplicación debilitada del experimento, de si los enunciados que autoriza sobre sus informaciones de base poseen la misma fortaleza probatoria cuando se aplican a las ciencias experimentales y a las ciencias de observación histórica; por el momento, basta con subrayar el optimismo que revisten sus argumentaciones, pues en el fondo aceptan la idea de que, en ciencias sociales, el razonamiento experimental está representado por el razonamiento estadístico, esto es, de que el razonamiento operado sobre "casos» históricos revela la misma lógica que la experimentación sobre hechos naturales, ya que reposan sobre la misma estructura formal (Simiand, 1922: 19). El problema consiste en que la postura durkheimiana, al fundar el razonamiento sociológico en un razonamiento comparativo estadístico, se muestra indiferente ante la textura empírica de los objetos de los cuales extrae sus medidas. De ese modo, logra minimizar, como dice Jean-Claude Passeron (1991: 166), el debilitamiento demostrativo que caracteriza el paso del razonamiento estadístico al razonamiento comparativo sobre «casos» históricos. ${ }^{32}$

Sea como fuere, esta apreciación no debería empañar la innovación del enfoque sociológico; haya o no acuerdo sobre su optimismo de fondo, el hecho es que la sociología durkheimiana aporta elementos interesantes como para poder empañar el alcance de sus críticas a los historiadores. Los sociólogos de L'Année Sociologique fueron pioneros en esta empresa: fueron los primeros en disociar lo psicológico de lo subjetivo y tratar de articular un campo de análisis donde las representaciones mentales se reorganizan «en función de parámetros (abstractos) que poco tienen que ver con las unidades (concretas, vulgares) delimitadas por la percepción de los actores». El resultado es la construcción de un dominio novedoso de objetos: el «hecho social», un objeto al que solo se

32. Esto no quiere decir, sin embargo, que se deba negar la cientificidad de las ciencias sociales. El propio Passeron admite la ruptura de la sociología de Durkheim frente al relato de los historiadores historizantes. Sin embargo, reconoce al mismo tiempo que la sociología intercala momentos de razonamiento natural y momentos de razonamiento experimental (estadístico). La sociología no se contenta con la variación de las propiedades distribuidas en una tabla de frecuencias; dicha tarea, aunque exprese un momento de "pureza» experimental, es todavía monosémica, y como tal no posee significación histórica alguna. Considerada en sí misma, la información de una tabla estadística no permite concluir si la variación de propiedades que distribuye una variable cualquiera es constante en las diferentes épocas (ceteribus paribus) o depende de un contexto histórico. Las discusiones de este tipo, propias de la enunciación sociológica (e histórica), presuponen razonamientos de carácter natural (Passeron, 1991: 206-219). 
puede acceder mediante un conjunto de técnicas y operaciones concertadas, en razón de las cuales se pueden abstraer los datos del contexto enunciativo (los enunciados de base) y reorganizarlos de acuerdo a una serie de variables construidas por el investigador. De ese modo, la investigación científica puede realizar mediciones y establecer regularidades sociales, al operar con una serie de objetos que poco tienen que ver con las unidades delimitadas (las prenociones) por el contexto originario de enunciación. De ahí, precisamente, el uso y la reivindicación de la estadística

\section{2. "La historia será cuantitativa o no será»: el papel de la estadística en la renovación de la ciencia histórica y el modelo de ciencia}

En el planteamiento de los sociólogos la estadística ocupa un lugar privilegiado. Gracias a ella, los saberes «históricos» (cuyos hechos se conocen siempre por vía indirecta) alcanzan momentos de razonamiento experimental. Durkheim y Simiand son conscientes de las limitaciones que caracterizan a la "experimentación» en sociología. En las ciencias naturales (biología, física, química), la observación empírica es el producto de la intervención consciente y artificial del investigador. Este último no solo está en condiciones de observar directamente los fenómenos, sino que también puede reproducir la misma experiencia en infinitas ocasiones. Es decir, puede manipular a su antojo las diferentes variables que intervienen en la ocurrencia de un suceso. El valor de la experimentación del laboratorio reside así en el hecho de que las constataciones elementales se realizan en circunstancias definidas, según métodos y reglas de construcción igualmente definidos (Simiand, 1922: 22).

Sin embargo, la mayoría de estas condiciones (reproductibilidad, observación directa, manipulación artificial de las variables...) no pueden satisfacerse en el ámbito de las ciencias sociales e históricas. Existe aquí, como admite Simiand (1922: 23), una «inferioridad inicial», si bien es cierto que tal condición no le impide tantear otra forma de experimentación posible para las ciencias sociales. Esta experimentación alternativa, dice, no puede ser otra que la investigación estadística, cuyo propósito básico consiste en acceder al plano de las regularidades sociales por medio del análisis cuantitativo de una serie de características (variables) extraídas de grupos o de una selección amplia de casos particulares, no siendo tales características extrapolables a los elementos individuales que los componen. ${ }^{33}$ El objetivo de la estadística consiste así en establecer los valores que adoptan las distintas variables en una serie cronológica: ver por ejemplo si a los valores adoptados por una le corresponden los valores adoptados por otra, etcétera (ibíd.: 7).

Simiand es consciente de que la finalidad de la estadística no es la mera colección cuantitativa. No se trata de cuantificar por cuantificar; si en efecto es importante la estadística es porque, a pesar de sus limitaciones en el campo social, constituye un potente instrumento de preparación de los datos. Datos, 
además, que no hablan de sucesos o acontecimientos cronológicos, sino de tendencias y fenómenos de larga duración que con frecuencia resultan imperceptibles desde la óptica del método histórico, de raigambre filológica. La crítica del joven sociólogo a Seignobos encuentra aquí su máxima expresión. Este último trabaja con objetos que no se prestan a procedimientos de investigación cuantitativa. Amparado en el ideal de un registro sin presupuestos, Seignobos rechaza el uso de la abstracción (estadística) en historia, al considerar esta opción incapaz de respetar la explicación que los propios actores hacen de su acción social. El verdadero espíritu "científico", dice, expresa un conocimiento "empírico" mediante un vocabulario igualmente "empírico» (Seignobos, 1907: 600).

Por su parte, Simiand reclama el uso de términos abstractos como requisito irrenunciable; lejos de deformar la realidad, las abstracciones son aquello que convierte los hechos de observación en objetos científicos, ya que otorgan los caracteres necesarios para traducir la experiencia singular de los agentes en una parcela de realidad susceptible de albergar regularidades sociales (Simiand, 1903: 120). A este respecto, cabe recordar que Simiand tan solo pone de manifiesto una concepción nomológica de la ciencia, según la cual toda pretensión de explicación científica «debe proceder construyendo un orden de razones que se aparta del orden de la vivencia particular». Si la historia, como dice Seignobos, es un conocimiento empírico, si su práctica se limita a comprobar la autenticidad documental del lenguaje vulgar (no técnico) utilizado por los actores, aquella se condena a una reproducción descriptiva del pasado. Se inhibe, pues, de la tarea de elaborar otras operaciones mediante las cuales es posible manifestar los presupuestos de la acción social de los sujetos, esto es, las condiciones que les predisponen a tener probabilidades objetivas desiguales, sea en el acceso a cierta clase de bienes y prácticas, sea en el mantenimiento de las aspiraciones subjetivas correspondientes.

De ese modo, Simiand se sitúa en las antípodas de la epistemología defendida por la "historia historizante». En lugar de concebir la ciencia como una copia o una reproducción de la realidad, el sociólogo plantea un esquema cercano al enfoque contemporáneo del proceder científico. Esto es así porque, a diferencia de otras formas de conocimiento, la ciencia se construye a partir del rechazo (o ruptura) del objeto preconstruido por la percepción, lo que significa que su práctica metodológica, además de objetivar ciertas parcelas de la realidad, necesita construir sus propios objetos de estudio, necesita operar con entidades teóricas que funcionen como índices relativos a una problemática, de manera que el estudio de estos últimos permita obtener informaciones sobre el estado y la evolución de una variable expresamente construida. Por eso, los hechos a los que alude Simiand no son datos que se impongan por su sola evidencia; son datos que presuponen siempre una carga teórica. En efecto, solo si hay una hipótesis o una codificación de trabajo previamente formulada, es posible trascender la descripción empírica de los fenómenos y generar un «efecto de conocimiento». Mientras no se efectúen operaciones centradas en la conceptualización de las informaciones de base, no habrá conocimiento cien- 
tífico, si por esto se entiende un saber cuyo objetivo no es la mera descripción de los enunciados protocolares sino la construcción de relaciones novedosas entre los hechos, relaciones que no eran evidentes antes de la labor de conceptualización pero que sin embargo son capaces de construir una «organización nueva de la observación histórica».

Así pues, el sociólogo no trata de hacer hablar a los suicidas, es él quien habla en su lugar, pero lo hace con el objeto de reconstruir una serie de realidades o fenómenos (ideologías, instituciones, etcétera) que no son observables en las informaciones de base que los agentes ofrecen de su experiencia de la acción social. En pocas palabras, los suicidas pueden hablar de las razones que les habrían llevado a cometer actos suicidas; el sociólogo, en cambio, deberá traducir tales informaciones de base en el metalenguaje propio de las ciencias sociales, eludiendo así el lenguaje «equivocado» o «miope» de los suicidas y haciendo ver en su lugar fenómenos como las regularidades sociales, la «anomia social», la «integración social», el «suicidio altruista», etcétera.

Por supuesto, tales indicaciones suponen una crítica de la máxima que L. von Ranke había legado a la historiografía, según la cual el deber de un historiador no consistía en juzgar moralmente el pasado, ni en instruir a sus contemporáneos, sino en producir un modelo de historia escrita «wie es eigentlich gewesen ist». Ahora bien, el tipo de objetividad reclamada por Ranke descansaba todavía en un análisis testimonial del documento: se suponía que lo único representable en él era su «dimensión consciente y subjetiva», el ámbito donde el autor del documento pone al descubierto los hechos y las intenciones que motivaron a los actores del pasado. Ranke utilizaba esta máxima en un sentido polémico: se trataba de oponerse a la «historia novelada» tipo Ivanhoe o a la idea de la historia como magistra vitae. Al incidir en el "wie es eigentlich gewesen ist», se pretendía hacer hincapié en las fuentes, en el análisis crítico de las fuentes y el disciplinamiento metódico de los historiadores. El problema es que esta reconstrucción crítica del pasado histórico se supeditaba al análisis filológico y a la dimensión "consciente de las huellas psicológicas inscritas en el documento». Se admitía, por un lado, la materialidad del texto, esto es, la idea de que el texto es capaz de proporcionar más información que la que expresa el contenido explícito del autor, ${ }^{34}$ pero, por otro, se limitaba el potencial de información disponible del documento a los esquemas planteados por un análisis centrando en la autenticidad de las fuentes, dando a entender que la única función de la crítica histórica consistía en mostrar primero la procedencia real del texto y determinar después si el contenido expresado en él resulta veraz o fidedigno. ${ }^{35}$

Por el contrario, el enfoque de Simiand sostiene una concepción distinta del documento, que prefigura en cierto modo la crítica realizada por la escue-

34. En esto consiste, precisamente, la crítica externa de las fuentes, de tipo diplomático y epigráfico. La presentación de esta crítica puede verse de manera paradigmática en Seignobos y Langlois (1898: 101-156).

35. Labor propia de la crítica interna (o de sinceridad) de las fuentes. Véase Langlois y Seignobos (1898: 157-211). 
la historiográfica de los Annales. En efecto, para él, al igual que para Lucien Febvre u otros historiadores, ${ }^{36}$ la cientificidad comienza con un trabajo previo de objetivación, de preparación y codificación de materiales. Pero una codificación, eso sí, diferente de la preceptiva metodológica que se había perfilado desde Mabillon y, después, la escuela metódica francesa (Seignobos y Langlois: 1898). Así, en lugar de limitar el análisis al horizonte de sentido impuesto por la óptica de las fuentes, el investigador debe comenzar objetivando los gestos y los códigos de naturaleza colectiva implícitos en los documentos, a fin de reconvertir el contenido explícito del texto en un dato o una entidad operatoria construida en función de una problemática establecida por el investigador, y susceptible por eso mismo de suscitar estrategias explicativas objetivas, no meramente finalistas o intencionales.

Si en el documento se buscan, como hace el historiador tradicional, acontecimientos individuales, más aún, explicaciones por los motivos (...) el documento no es, de hecho, materia de trabajo científico (...). Pero si la investigación está dirigida hacia "la institución» y no hacia "el acontecimiento", hacia las relaciones objetivas entre los fenómenos y no hacia las intenciones y los fines concebidos, esta se encuentra a menudo, en realidad, con que llega al hecho estudiado no por intermediación de un espíritu, sino directamente (...) Costumbres, representaciones colectivas, formas sociales, por lo común son inconscientemente registrados o dejan automáticamente huellas que el historiador llama documentos. (Simiand, 1903: 135)

De lo cual, también se deriva una crítica radical de los supuestos esencialistas que todavía subsisten en la máxima de Ranke:

A fuerza de repetir, con la escuela moderna, que la historia es una representación del pasado exacta, imparcial, sin fines tendenciosos ni moralistas (...) se llega si no a olvidar sí a no prestar suficiente atención al hecho de que «exacto» no quiere decir «integral», que «imparcial» no quiere decir «automático», que «sin tendencia, sin preocupación literaria» no quiere decir «sin preconcepto, sin elección» (...). (Simiand, 1903: 140)

Desde este punto de vista, el conocimiento no es una copia de la realidad, es una práctica teórica cuyas hipótesis y codificaciones metodológicas influyen en la ordenación conceptual de los hechos. Así, «lo que aparece o se deja ver en el documento", no es lo que este es de suyo, sino lo que la propia tradición o la comunidad científica, materializada en hábitos de lectura o procedimientos analíticos, permite que aparezca. Simiand es tajante en este punto. No existe un registro sin supuestos:

36. Este trabajo previo de codificación de las fuentes, que es al mismo tiempo un distanciamiento de la óptica de las mismas, se observa en múltiples autores, muchos de ellos adscritos a escuelas y procedencias diferentes. Véanse Febvre (1952: 428), Foucault (1969: 9-30), Pomian (1999: 345-404), Furet (en Le Goff y Nora, 1974), Vovelle (en Le Goff, 1978: 88-90), entre otros. 
la representación del pasado de la humanidad que puede y quiere darnos la historia no es de ninguna forma una "fotografía del pasado", ni una reproducción integral (...). La obra histórica más tosca, el análisis menos refinado de los textos, la recogida más pasiva de los documentos, es ya una elección, implica alguna eliminación, supone alguna preconcepción del espíritu. (ibíd.: 141)

Ahora bien, el propósito de Simiand no se salda con una crítica a una forma especial de hacer historiografía; su objetivo es vislumbrar un horizonte donde la clave del proceso cognoscitivo deje de estar prisionera de las evidencias empíricas inmediatas; se trata, en definitiva, de plantear que la secuencia cognitiva establecida por Seignobos, al limitarse a la experiencia de los agentes, corre el riesgo de encerrar la práctica investigativa en un modelo restringido de análisis, «dando por explicado aquello que precisamente hay que explicar».

La ciencia, sostiene, no estudia las cosas tal como se dan en la percepción; más bien somete estas últimas a una consideración previa (concertada y variable en cada ciencia) en virtud de la cual se hace de ellas algo objetivable (por tanto, predecible o comparable) según determinados parámetros. Parámetros, además, en los que no habría que ver la transliteración conceptual de una esfera de realidad dada de antemano, sino una imposición formal puesta en práctica por el entendimiento. Durkheim expresa esta idea en su prólogo a la segunda edición de Las reglas del método sociológico, al percatarse de los malentendidos que puede acarrear la interpretación metafísica de la primera de sus reglas. "Tratar como cosas a los hechos de un cierto orden no es, pues, clasificarlos en tal o cual categoría de lo real; es mantener frente a ellos una actitud mental determinada» (Durkheim, 1895: 10). De este modo, el sociólogo pone de manifiesto su defensa de la «externalidad» de los hechos, a condición de que esta última se realice «sin confundir esa disposición mental respecto a los objetos con una asignación estrictamente ontológica». ${ }^{37}$

No quiere esto decir, sin embargo, que haya que renunciar al ideal de «objetividad»; al contrario, significa que la noción misma de objetividad, tal como se plantea en Simiand, deja de ser reducida a la forma grosera de una «exterioridad dada». No se trata, pues, de una propiedad inherente de los hechos, sino de una propiedad que lo real adquiere al ser lingüísticamente codificado, al ser investido por criterios de objetivación analítica. De ese modo, las reflexiones de Simiand resultan, en cierto sentido, contemporáneas:

(...) La objetividad no es una propiedad inherente a las cosas (...) el objeto, la cosa del mundo que llamamos exterior, no es, desde el punto de vista del conocimiento empírico, más que un simple conjunto de sensaciones constituido en todo a través de la abstracción. (Simiand, 1903: 117)

Ahora bien, de aquí no debería sospecharse ninguna forma de idealismo encubierto, si acaso, un idealismo versado en la dimensión semántica de las

37. Véanse Bourdieu, Passeron y Chamboredon (1968: 51-54) y Blanckaert (en Revel et al., 2006: 127-130). 
formas de realismo, pero no un ataque a su dimensión ontológica. Más que una imagen verbal de una realidad externa y preexistente, la objetivación (las técnicas de objetivación) es una "construcción analítica que instala un dispositivo de conmensuración de registros y establece convenciones para interpretarlos». Su propósito es proceder al recorte semántico de la realidad e instituir un patrón teórico por medio del cual se definen los rasgos pertinentes de análisis, lo que debe contar como «dato». En este sentido, el propósito de la práctica científica no consiste en el estudio de una hipotética realidad «en sí», sino en el análisis de un objeto que ha sido teóricamente construido. Y cuando decimos construido, no se quiere decir que la ciencia prescinda del carácter externo de los hechos, pero sí de las configuraciones de sentido - las prenociones, las inducciones espontáneas- que tienden a imponerse como estructuras de objeto, y que sin embargo no son más que un producto que recibe su evidencia y su autoridad de la función social que cumple, y no de una elaboración científica y reflexiva (Durkheim, 1895: 40-41).

Esta advertencia es especialmente clara en el caso de la sociología durkheimiana, donde se percibe una actitud ambigua frente a la experiencia: pues por un lado, presta atención a esta última, ya que sin ella no habría materia de conocimiento, pero por otro, mantiene una duda metódica hacia la experiencia entendida como "explicitación de lo vivido», esto es, como discurso que desconoce el carácter de «situación impuesta» (objetivamente estructurada) desde el cual se elabora la propia vivencia individual.

Así, a diferencia de la historia historizante, que construye sus objetos de investigación a partir de opciones no explícitas (prenociones) o problemáticas políticas (búsqueda de los orígenes, legitimaciones políticas), el enfoque de Simiand se decanta por un estudio centrado en el plano de la evolución formal de los hechos, lo que supone un cambio en la manera de trabajar la dimensión temporal del pasado (Revel, 1979: 1364). Esta decisión, como se ha dicho antes, trajo consigo importantes cambios desde el punto de vista explicativo. Las causas ya no residen en las voluntades de los sujetos, sino en la trayectoria que adquiere la evolución formal de los fenómenos, toda vez que estos últimos hayan sido reducidos al plano formal de sus contenidos, en tanto que portadores de información. ${ }^{38}$ En este sentido, queda excluida de la investigación histórica «la tendencia a buscar el orden de las causas en la sucesión cronológica y los fines de los agentes». ${ }^{39}$ Existen numerosos casos donde los hechos poste-

38. Por supuesto, el planteamiento estadístico defendido por Simiand tiene sus peligros. Aprehender los fenómenos al nivel de sus formas (p. ej. curvas de precios) puede conducir a reificar la visión del proceso histórico, al entender que solo los elementos formales (aquello que se puede medir) valen para constituirse en los motores esenciales del proceso histórico. Una crítica desde la microhistoria italiana se puede observar en Gribaudi (en Revel, 1996: 113-140).

39. Para Seignobos (1908: 230), la causa o el antecedente inmediato de un suceso ha de buscarse en las representaciones conscientes de los documentos, no en las tendencias materiales. De ahí su predilección por la historia del poder político y el estudio de los acontecimientos: son ellos los que, a su juicio, proporcionan la homogeneidad temporal al resto de los fenómenos humanos (Seignobos y Langlois, 1898: 242). 
riores no se hacen inteligibles gracias a los anteriores, pues entre ambos media un tipo de determinaciones abstractas - ejercidas, pero no representadas - que las técnicas de análisis filológico no son capaces de objetivar.

En otras palabras, al buscar las regularidades sociales, Simiand no indaga en el sentido que los sujetos dan a su acción, sino en las estructuras que hacen objetivamente posible que un suceso o una acción hayan tenido efectivamente lugar. Se trata así de pensar la diacronía histórica como una estructura de cambio compleja, en donde los rasgos pertinentes de análisis no se buscan en los funcionamientos biográficos de los individuos, como admitía en cierto modo Seignobos, ${ }^{40}$ sino en la dinámica de las diferentes propiedades formales de una población, ya que estas últimas afectan al modo en que los sujetos se inscriben (y se perciben) en la estructura social.

De ese modo, Simiand (1906: 558) reclama una inversión de perspectiva: preguntar no tanto (o no solo) «qué ideas han guiado al sujeto?», sino más bien "¿por qué un hecho o un conjunto de hechos contingentes fueron susceptibles de adquirir un poder de transformación tan poderoso?», ¿qué tipo de tensiones existían en la estructura social para que un suceso de tales características pudiera desencadenar "por sí solo» un cambio a gran escala? ${ }^{31}$

En palabras del sociólogo:

En multitud de países y en multitud de épocas, encontramos pequeños grupos de agitadores (...); sin embargo, la acción de unos agitadores no es suficiente para producir una revolución en el gobierno (...) Las causas profundas, las verdaderas causas son omitidas: la desintegración social que supuso la Revolución y que sobrevivió a una restauración fáctica del Antiguo Régimen, una inadaptación de los gobiernos restablecidos a las nuevas tendencias sociales, una disposición colectiva de los ánimos, etc. (...) En la guerra de 1870, se señala la acción de dos individuos, Bismarck y Napoleón III, y se omite toda la larga preparación de instituciones y del espíritu social que se ha desarrollado en Alemania durante todo el siglo XIX, y sin la cual el genio mismo de Bismark no habría tenido lugar (...) se olvidan simplemente todos los factores sociales (...). (Simiand, 1903: 133-134)

La postura de Simiand es que, como los historiadores prescinden de tales cuestiones, se condenan a un enfoque restringido de la síntesis histórica. Creen operar con explicaciones causales y en realidad no sobrepasan el ámbito des-

40. Aunque sea críticamente, Seignobos acaba admitiendo la necesidad del estudio para la historia de los «grandes» individuos, los que disponen de una cobertura de acción social mayor. Véase Seignobos y Langlois (1898: 244-245). Para un uso no heroico de lo biográfico, centrado en el estudio cualitativo de biografías anónimas en donde aparecen temas nuevos como la emoción y las mentalidades, véase Loriga (en Revel, 1996: 209-231).

41. El lector informado sabrá percatarse de las similitudes que tales cuestiones mantienen con algunos pasajes de la obra de Montesquieu: «Si una causa en particular, como el resultado accidental de una batalla, ha arruinado a un Estado, entonces existió una causa general que fue la que determinó la caída de dicho estado como consecuencia de una sola batalla». Esta máxima, sugerida en Consideraciones sobre las causas de la grandeza y decadencia de los romanos, era conocida por Durkheim (1892: 67). 
criptivo de los fenómenos. Ahora bien, para realizar estas inferencias es preciso fijar la mirada, como hacen las ciencias naturales, en los fenómenos recurrentes, y no en los aspectos contingentes. El hecho de operar con este tipo de datos - datos explícitamente construidos para expresar la regularidad de los hechos- es lo que permite al historiador actuar como un científico, ya que puede inducir relaciones constantes e inferir nexos objetivos de causalidad. De ahí la contundencia de Simiand:

si el estudio de los hechos humanos quiere constituirse en ciencia positiva, debe apartarse de los hechos únicos para tomar en consideración los hechos que se repiten, es decir, debe descartar lo accidental para agarrarse a lo regular, debe eliminar lo individual para estudiar lo social. (Simiand, 1903: 131)

Tal ambicioso programa, como recuerda F. J. Devoto (1992: 61), debe culminar con la célebre requisitoria contra los ídolos de la tribu de los historiadores: lo político, lo individual y lo cronológico.

\section{Conclusión}

En el estudio presentado se ha podido comprobar la importancia del presente debate para la historia de la sociología y la historia social en Francia. En él se encuentran enunciadas las claves que van a guiar el programa de trabajo desarrollado por algunos investigadores tan célebres como Ernest Labrousse. ${ }^{42} \mathrm{De}$ hecho, no es difícil adivinar en sus trabajos, centrados en la reconstrucción de series, el tratamiento de datos numéricos, la confrontación entre las tendencias de los precios o el movimiento de la renta de la tierra, ejemplos específicos de las máximas metodológicas planteadas por Simiand: en ellos se puede vislumbrar en acto la superación del hecho singular por el hecho repetitivo, el carácter nomotético de la ciencia histórica, la introducción de los métodos cuantitativos o el intento de ensayar una estrategia explicativa partiendo de una comprensión holística de la estructuración social. ${ }^{43} \mathrm{Y}$ algo parecido se puede decir respecto a las líneas de trabajo inauguradas por los Annales. No es preciso ser un especialista en la materia para percatarse de la similitud entre la crítica durkheimiana

42. Fiel a la idea de realizar una historia de las fluctuaciones económicas en la larga duración, Labrousse escribió dos trabajos (Esquisse du mouvement des prix des revenus au XVIII siècle, de 1933, y La crise de l'économie à la fin de l'Ancien Régime et au debut de la Révolution, de 1944) que ejercieron una gran influencia en la historia de las décadas de 1940 y 1950. La diferencia quizá con Simiand es que se sirve de los movimientos de los precios y de las rentas para reconstruir los niveles de vida de los diferentes grupos sociales en el Antiguo Régimen. Hay quizá una vocación más histórica que económica.

43. Tal era la deuda con la obra de Simiand, que el propio Braudel, director en 1960 de la revista Annales, reedita el artículo de Simiand «Método histórico y ciencia social». Y se hace, además, con el objetivo expreso de dar a conocer a los jóvenes historiadores las sugerentes críticas que a juicio de Braudel se podían encontrar en el joven Simiand, así como de permitir evaluar a las nuevas generaciones el camino recorrido por la historia y las ciencias sociales en la primera mitad del siglo xx. Véase Annales, 15 (1), 1960 (83-119). 
de las prenociones y la "historia-problema» de Lucien Febvre ${ }^{44}$ o la complejidad del tiempo social de Fernand Braudel. ${ }^{45}$ En todos estos casos, se asiste al intento de construir una organización nueva de la observación histórica, tal que esta última permita visibilizar recurrencias y variaciones mediante las cuales es posible inferir nexos de causalidad abstractos, alejados del modelo intencional e ideográfico de la historia del siglo XIX.

Así, aunque la disputa no trajera consigo la transformación inmediata del campo de investigación histórica, ${ }^{46}$ sí ejerció una importante influencia en el espacio de la discusión teórica. Se ampliaron los objetos de investigación y se comenzó a discutir, dentro de la práctica profesional, acerca de la red de evidencias y anticipaciones procedimentales que hasta ese momento habían sido hegemónicas. De ahí la pertinencia de la presente disputa: lejos de ser un episodio anecdótico, constituye un momento ineludible para entender la apertura de las investigaciones históricas al estudio de lo social y lo económico. La postura de Simiand es aquí paradigmática; su crítica de los historiadores no es una negación estricta de lo político, es el intento de reorganizar la observación histórica y hacer inteligibles en la «larga duración» ${ }^{47}$ fenómenos que antes (antes de la teoría) solo se percibían como una polvareda de actos dispersos. Y tampoco se trata de una negación de la historia nacional, como se suele decir, sino de una reordenación de la historia sobre marcos y cuestionarios más amplios, lo cual precisaba dos tipos de exigencias que tal vez hoy, transcurrido el siglo Xx, puedan parecer triviales, pero que en su momento emergieron como potentes e innovadoras claves de análisis en materia de investigación histórica y social:

- Por un lado, el descabezamiento de la política como clave explicativa de la historia.

- Y por otro, el intento de fijar la práctica analítica (sus marcos clasificatorios, sus objetos, sus problemáticas) en los términos en que han sido fijados

44. Así expresa su deuda Febvre (1930: 583): «Cuando a los veinte años, con sentimientos mezclados de admiración y de rebeldía instintiva, leíamos L'Année Sociologique, una de las novedades que más nos llamaba la atención, ¿̇no era acaso ese esfuerzo perpetuo de reacondicionamientos, de readaptación de los marcos clasificatorios que, de volumen en volumen, se flexibilizaba, se modificaba...?».

45. No fue tan clara sin embargo la influencia de Simiand en los trabajos surgidos en torno a las revistas Past and Present o Social History, donde los historiadores ensayaban diferentes formas de historia social partiendo de una revaloración de la human agency. Especialmente significativos son los trabajos del marxismo británico, sobre todo de Edward Pamel Thompson, Eric Hobsbawm, Chistopher Hill, Rodney Hilton.

46. Entre 1919 y 1938 el discurso histórico sigue confinado en la esfera política: a cuyo cometido se dedican más de la mitad de las tesis y más de las tres cuartas partes de los DES. Todo ello demuestra una gran pervivencia de los determinismos cuestionados una generación antes por Simiand. Véase Dosse (1987: 22).

47. Por supuesto, Simiand jamás utilizó esta expresión, de factura braudeliana. Sin embargo, el uso de la misma nos sirve para poner de manifiesto la similitud de la perspectiva de análisis desarrollada por Simiand en sus trabajos de historia económica. Recuérdese por ejemplo la fase A y B, construidas a través del movimiento de los precios y las fluctuaciones económicas (Simiand, 1932). 
por el investigador, y no en los términos con que vienen calificados en los propios documentos.

Si este debate resulta interesante no es solo por una cuestión de arqueología disciplinar, sino porque en él se hace una apelación expresa — quizá la primeraa la necesidad de integrar una actitud reflexiva en el protocolo de investigación. La nueva historiografía no se puede limitar al establecimiento de hechos cuyo sentido es dado de antemano; tiene que dirigir preguntas y operar un cambio en las maneras de procesar las fuentes, a fin de evitar que la «práctica investigativa quede reocupada por dispositivos ideológicos implícitos», tanto más operativos cuanto mayor es su desconocimiento por parte del investigador.

Posiblemente, uno de los mayores aportes del presente debate es haber contribuido a explicitar este tipo de cuestiones. El ataque que ejerce Simiand contra los historiadores no es un ajuste de cuentas gratuito, es ante todo el intento de visibilizar aquellos obstáculos (ídolos) que impiden renovar la ciencia histórica y hacer que su investigación se enmarque al margen de los objetos prefabricados por la doxa del momento. Es en este sentido que aquí se reivindica la pertinencia de la disputa entre Simiand y Seignobos, lo cual no implica aceptar todos los asertos de la sociología durkheimiana, pero sí tal vez la más fértil de sus enseñanzas, a saber, la necesidad de reflexionar sobre los marcos clasificatorios de la investigación.

\section{Referencias bibliográficas}

Barret-Kriegel, B. (1988). Les Académies de l'histoire. París: PUF.

BerR, H. (1900). «Sur notre programme». Revue de Synthèse Historique, I/1, 1-8.

- (1902). «Les rapports de l'histoire $\&$ des sciences sociales. D'après M. Seignobos». Revue de synthèse historique, 4, 293-302.

Besnard, Ph. (1986). «L'impérialisme sociologique face a l'Histoire». En: aAvv. Historiens et sociologues aujourd'hui, 27-35. París: Éditions du CNRS.

Borlandi, M. (2017). «Sociologie et histoire: la contribution de Durkheim

Bouglé, C. (1904). «Xénopol, Berr, Simiand, Croce. Discussions sur les rapports de l'histoire avec les sciences naturelles et les sciences sociales». L'Année Sociologique, 7, 148-151.

Bourdieu, L. (1888). L'Histoire et les historiens. Essai critique sur l'histoire considérée comme une science positive. París: Félix Alcan.

Bourdieu, P.; Passeron, J.-C.; Chamboredon, J.-C. (1968). El oficio de sociólogo. Presupuestos epistemológicos, 2005. Madrid: Siglo xxI.

Boutier, J.; Passeron, J.-C. (eds.) (2006). Qu'est-ce qu'une discipline? París: Éditions de L'EHESS..

BULLETIN DE LA SOCIÉTÉ D'HistoIRe Moderne (1903). Séance du 3 Janvier, 73-77.

Burke, P. (1992). History and Social Theory. Nueva York: Cornell University Press.

Carbonell, Ch.-O. (1976). Histoire et historiens. Une mutation idéologique des historiens français, 1865-1885. Toulouse: Privat.

- (1978). "L'histoire dite "positiviste" en France». Romantisme, 21-22, 173-185. <https://doi.org/10.3406/roman.1978.5216>.

Collingwood, R. G. (1952). Idea de historia. México: FCE. 
Devoto, F. (1992). Entre Taine y Braudel. Itinerarios de la historiografía francesa contemporánea. Buenos Aires: Biblos.

Dilthey, W. (1883). Einleitung in die Geisteswissenschaten. Leipzig: Duncker \& Humblet.

Domínguez, D. J. (2019). «El ejercicio histórico como ejercicio del poder: el Cabinet des chartes y la sociogenesis de la archivística francesa». Historia y Memoria, 19, 269-308. <https:/doi.org/10.19053/20275137.n19.2019.8585>.

Dosse, F. (1987). L'histoire en miettes. Des Annales à la «nouvelle histoire». París: La Découverte.

Durkheim, É. (1888a). «Cours de science sociale. Leçon d'ouverture». Revue Internationale de l'Enseignement Supérieur, 15, 23-48. París: G. Masson Éditeur. $<$ https://doi.org/10.1522/cla.due.cou4>.

- (1888b). «Introduction a la sociologie de la famille». Annales de la Faculté des Lettres de Bordeaux, 10, 257-281. París: Ernest Léroux. $<$ https://doi.org/10.1522/cla.due.int2>.

- (1892). «La contribution de Montesquieu à la constitution de la science sociale». En: Montesquieu et Rousseau, précurseurs de la sociologie, 25-113. París: Librairie Marcel Rivière et Cie.

- (1895). Les régles de la méthode sociologique. París: Félix Alcan Éditeur.

- (1898a). "Préface de L’Année Sociologique». L'Année Sociologique, n. 1 (18961897), I-VII. París: Ancien Librairie Germer Bailliére y Félix Alcan Éditeur.

- (1898b). "Répresentations individuelles et représentations collectives». Revue de Métaphysique et de Morale, 6. $<$ https://doi.org/10.1522/cla.due.rep1>.

- (1902). «Ch. Seignobos: La méthode historique appliquée aux sciences sociales». l'Année sociologique, Cinquième année, 123-127.

- (1909). «Sociologie et sciences sociales». De la méthode en sciences sociales. París: Félix Alcan, 259-285. <https://doi.org/10.1522/cla.due.soc6>.

Durkheim, É.; Fauconnet, P. (1903). Sociologie et sciences sociales». En: Karady, V. (ed.). Textes. 121-159. París: Ed. de Minuit, 1975. $<$ https://doi.org/10.1522/cla.due.soc4>.

Febvre, L. (1930). «Histoire, économie et statistique». Annales d'Histoire Économique et Sociale, II, 581-590.

- (1952). Combats pour l'histoire. París: Armand Colin, 1992.

Foucault, M. (1969). La arqueología del saber. México: Siglo XXI, 2007.

Goldthorpe, J. H. (1991). "The uses of history in sociology: reflections on some recent tendencies». The British Journal of Sociology, 42 (2), 211-230. $<$ https://doi.org/10.2307/590368>.

Halbwachs, M. (1935). «La statistique en sociologie». La statistique, ses applications, les problèmes qu'elle soulève. París: Les Presses Universitaires de France. $<$ https://doi.org/10.1522/cla.ham.sta>.

JANET, P. (1889). L'automatisme psychologique. Essai de psychologie expérimentale sur les formes inférieures de l'activité humaine. París: Félix Alcan.

Karady, V. (1976). "Durkheim, les sciences sociales et l'Université: bilan d'un semiéchec». Revue Française de Sociologie, 17-2, 267-311. <https://doi.org/10.2307/3321249>.

- (1979). "Stratégies de réussite et modes de faire-valoir de la sociologie chez les durkheimiens». Revue Française de Sociologie, 20-1, 49-82. <https://doi.org/10.2307/3321264>. 
Keylor, W. R. (1975). Academy and Community. The foundation of the French Historical Profession. Cambridge, Massachusetts: Harvard University Press.

Labrousse, E. (1933). Esquisse du mouvement des prix des revenus au XVIII siècle. París: Librairie Dalloz.

- (1944). La crise de l'économie française à la fin de l'Ancien Régime et au début de la Révolution. París: Presses Universitaires de France.

Lacombe, P. (1894). De l'histoire considérée comme science. París: Hachette.

- (1900). «La science de l'histoire d'après M. Xénopol». Revue de Synthèse Historique, $1,28-51$.

LAMPrecht, Karl (1900a). «La méthode historique en Allemagne». Revue de Synthèse Historique, I/1, 21-27.

(1900b). Die kulturhistorische Methode. Berlin: R. Gaertner.

Le Goff, J. (dir.) (1978). La nouvelle Histoire. París: Éditions Complexe, 2006.

Le Goff, J.; Nora, P. (dir.) (1974). Hacer la historia. Volumen 1. Barcelona: Editorial Laia, 1985.

Leroux, R. (1998). Histoire et sociologie en France. De l'histoire-science à la sociologie durkheimienne. París: Presses Universitaires de France.

Mantoux, P. (1903). "Histoire et Sociologie». Revue de Synthèse Historique, 8, 121-127.

Menger, C. (1871). Grundsätze der Volkswirtschaftslehre. Berlin: Braumüller.

- (1883). Untersuchungen über die Methode der Sozialwissenschaften und der politischen ökonomie insbesondere. Leipzig: Duncker \& Humblot.

Mucchielli, L. (1998). La découverte du social. Naissance de la sociologie en France (1870-1914). París: La Découverte.

Noiriel, G. (1990). «Naissance du métier d'historien». Genèses, 1, 58-85. <https://doi.org/10.3406/genes.1990.1014>.

- (2003). "L'éthique de la discussion chez F. Simiand. A propos de deux conférences sur l'histoire (1903-1906)». Penser avec, penser contre: itinéraire d'un historien, 47-61. París: Belin.

«Notes, Questions ET Discussions» (1905). Revue de Synthèse Historique, X-1/28, 369-372.

Ortega, J. A. (1980). Teoría y crítica de la historia cientifico-idealista alemana. México: UNAM.

Parodi, D. (1899). «Introduction aux études historiques, de Charles Victor Langlois et Charles Seignobos». L'Année sociologique, deuxième année, 142-145.

Passeron, J.-C. (1991). El razonamiento sociológico: el espacio comparativo de las pruebas históricas. Madrid: Siglo XXI, $201 \mathrm{I}$.

Pomian, K. (1984). L'ordre du temps. París: Gallimard.

- (1999). Sur l'histoire. París: Gallimard.

Pournin, M. (1904). «Rapports de la Sociologie avec l'Histoire». Revue Internationale de Sociologie, 12, 161-167.

Ramos, R. (1999). La sociología de Émile Durkheim. Patología social, tiempo, religión. Madrid: CIS.

Réberioux, M. (1983). «Le débat de 1903: historiens et sociologues». En: CarboNell, Ch. O. (ed.). Au berceau des Annales. Le milieu strasbourgeois. L'histoire en France au début du XXe siècle, 219-230. Toulouse: Presses de l'Institut d'Études Politiques de Toulouse.

Revel, J. (1979). «Histoire et sciences sociales: les paradigmes des Annales». Annales ESC, 34 (6), 1360-1376. <https://doi.org/10.3406/ahess.1979.294131>. 
- (ed.) (1996). Jeux dechelles. La micro-analyse à l'experience. París: Gallimard, La Seuil.

- (1999). «Histoire et sciences sociales: lectures d'un debat français autour de 1900». En: Bodeker, H. E.; Reill, P. H.; Schlumbohm, J. (eds.). Wissenschaft als kulturelle Praxis, 1750-1900, 377-399. Gottingen: Vandenhoeck \& Ruprecht.

Rickert, Heinrich (1899). Kulturwissenschaft und Naturwissenschatf. Ein Vortrag, Freiburg am Brisgau. Leipzig: Tübingen.

- (1901). "Les quatre modes de l'“Universel" en histoire». Revue de Synthèse Historique, II-2/5, 121-140.

Sevillano, F. (2018). «La controversia finisecular sobre el método histórico en Alemania y Francia (1883-1908)». Hispania, vol. LXXVIII, 258, 193-217. <https://doi.org/10.3989/hispania.2018.007>

Schmoller, G. (1883). "Zur Methodologie der Staats- und Sozialwissenschaften». Jahrbuch für Gesetzgebung, Verwaltung und Volkswittschaft im deutschen Reich, 7, 239-258.

Seignobos, Ch. (1901). El método histórico aplicado a las ciencias sociales. Madrid: Daniel Jorro, 1923.

- (1907). "Les conditions pratiques de la recherche des causes dans le travail historique. Séance du 30 mai 1907». Bulletin de la Société Française de Philosophie, 7. París.

- (1908). «L'inconnu et l'inconscient en histoire. Séance du 28 mai 1908». Bulletin de la Société Française de Philosophie. 8, 217-247.

- (1934). Études de politique et d'histoire. París: PUF.

- (1953). «La dernière lettre de Ch. Seignobos a Ferdinand Lot». Revue Historique, 77 (CCX), 1-12.

Seignobos, Ch.; Langlois, Ch.-V. (1898). Introducción a los estudios históricos. Alicante: Universidad de Alicante, 2003.

Simiand, F. (1899). "Déduction et observation psychologique en économie sociale». Revue de Métaphysique et de Morale, 7 (4), 446-462.

- (1903). «Méthode historique et science sociale. Étude critique d'après les ouvrages récents de M. Lacombe et de M. Seignobos». En: Cedronio, M. (ed.). Méthode historique et sciences sociales, 113-169. París: Éditions des Archives Contemporaines. <https://doi.org/10.1522/cla.sif.met2>.

- (1906). «La causalité en histoire. Séance du 31 mai 1906». Bulletin de la Société Française de Philosophie, 6. París.

- (1922). Statistique et expérience. Remarques de méthode. París: Librairie des Sciences Politiques et Sociales.

- (1932). Les fluctuations économiques à longue periode et la crise mondiale. París: Félix Alcan.

Spencer, H. (1859). «What Knouledge is of Most Worth?». Essays on Education, Etc, 19-29. Londres: Everyman's Library (1911). <https://doi.org/10.1037/12158-001>.

Tapia Alberfi, F. (2015). Fundamentos de la construcción del pensamiento sociológico de Émile Durkheim. Universidad del País Vasco.

VÁzQuez García, F. (1989). Estudios de teoría y metodología del saber histórico. Cádiz: Universidad de Cádiz.

WeILer, V. (2010). «La versión psicogenética de la historia cultural. A propósito de los cien años del Instituto de Historia Cultural y Universal en Leipzig». Anuario Colombiano de Historia Socialy de la Cultura, 37 (1), 227-267. 